\title{
Análise das características da aprendizagem de astronomia no ensino médio nos municípios de Rio Grande da Serra, Ribeirão Pires e Mauá (Characteristical analysis of high school astronomy's learning in Rio Grande da Serra, Ribeirão Pires and Mauá)
}

\author{
Rachel Zuchi Faria ${ }^{1}$ e Marcos Rincon Voelzke \\ Departamento de Informática, Centro de Ciências Exatas e Tecnológicas, \\ Universidade Cruzeiro do Sul, São Paulo, SP, Brasil \\ Recebido em 20/6/2008; Aceito em 24/9/2008; Publicado em 27/2/2009
}

\begin{abstract}
Apesar de a astronomia ser uma das mais antigas ciências e de ter contribuído para o desenvolvimento humano e tecnológico, raramente seus conceitos são ensinados aos jovens em idade escolar. A presente pesquisa discute dois aspectos relacionados com a abordagem da astronomia. O primeiro aspecto é se ela está sendo abordada pelos professores do ensino médio e o segundo aborda a maneira como ela está sendo ensinada pelos professores. Optou-se pela aplicação de um questionário com professores que ministram a disciplina de física, os quais trabalham em escolas estaduais nos municípios de Rio Grande da Serra, Ribeirão Pires e Mauá, em São Paulo. Dos $66,2 \%$ dos professores que responderam ao questionário nos três municípios pesquisados, $57,4 \%$ não abordaram nenhum tópico de astronomia, 89,4\% não utilizaram qualquer tipo de programa computacional, $70,2 \%$ não utilizaram laboratório, $83,0 \%$ nunca levaram os alunos a museus e ou planetários e 38,3\% não indicaram qualquer tipo de revista ou livro sobre astronomia aos seus alunos. Embora a maioria dos professores reconheça que o conteúdo de astronomia pode influir na formação do aluno, os mesmos não incluem o tema em seus planejamentos escolares.
\end{abstract}

Palavras-chave: ensino de astronomia, popularização da astronomia.

Even though astronomy is one of the oldest science that contributes to the human and technological development, its concepts are rarely taught for students of high school. The present research discusses two aspects related to the teaching of astronomy. The first aspect is to know whether astronomy is discussed in high school classes and the second on is related to the way how teachers approach astronomy. In order to find out this, a questionnaire was applied for the teachers who teach physics classes and work in state schools in Rio Grande da Serra, Ribeirão Pires and Mauá in São Paulo. From $66.2 \%$ of the teachers who answered to the questionnaire in the three chosen cities, $57.4 \%$ did not discuss any subject about astronomy, $89.4 \%$ did not use any kind of computer program, $70.2 \%$ did not use laboratory, $83.0 \%$ never took the students for museums or observatories and $38.3 \%$ did not indicate any kind magazine or book about astronomy. Although the majority of the teachers admit that the astronomy content influences the education of the student, they do not include the subject in their planning.

Keywords: astronomy teaching, astronomy literacy.

\section{Introdução}

A lei n. 9.394 de Diretrizes e Bases (LDB) [1] a partir de sua promulgação em 20 de dezembro de 1996, passa a considerar o ensino médio (EM) como etapa final da educação básica, tendo como finalidade fornecer meios para o educando progredir no trabalho, na continuação dos estudos e garantir ao mesmo uma formação comum para o exercício da cidadania. Em 1999 os Parâmetros Curriculares Nacionais (PCN) [2] propõem que o aprendizado deva ser entendido através de competências e habilidades a serem desenvolvidas pelos professores junto

\footnotetext{
${ }^{1}$ E-mail: raczuchi@uol.com.br.

aos alunos por área de conhecimento.

De acordo com os PCN [2] as competências e habilidades dividem-se em: representação e comunicação, onde se procura desenvolver a capacidade de comunicação; investigação e compreensão, onde se tenta desenvolver a capacidade de questionar processos naturais e tecnológicos, identificando regularidades, apresentando interpretações e prevendo evoluções como também desenvolver o raciocínio e a capacidade de aprender; contextualização sócio-cultural que tenta compreender e utilizar a ciência, como elemento de interpretação e intervenção e a tecnologia como conheci- 
mento sistemático de sentido prático. Diante desse novo panorama, faz-se necessária uma contextualização do ensino e com certeza a uma modificação no papel do professor.

Esta modificação no papel do professor passa por sua formação e deve valorizar o que Pimenta [3] denomina por professor reflexivo; aquele profissional em processo contínuo de formação que reelabora seu saber inicial a partir de sua vivência prática nos contextos escolares.

Neste contexto, a física deixa de ser vista de forma desarticulada como sinônimo de leis e fórmulas e de acordo com Orientações Educacionais Complementares aos Parâmetros Curriculares Nacionais $\left(\mathrm{PCN}^{+}\right)$[4] "passa a ser reconhecida como um processo cuja construção ocorreu ao longo da história da humanidade, impregnada de contribuições culturais, econômicas e sociais, que vem resultando no desenvolvimento de diferentes tecnologias e, por sua vez, por elas impulsionado".

Diante disso, uma nova maneira de abordar os conteúdos de física se faz necessária. Os $\mathrm{PCN}^{+}$privilegiam seis temas estruturadores com abrangência para organizar o ensino de física: Movimentos: variações e conservações; calor, ambiente, fontes e usos de energia; equipamentos eletromagnéticos e telecomunicações; som, imagem e informação; matéria e radiação; universo, terra e vida.

O tema estruturador privilegiado por esta pesquisa foi Universo, Terra e Vida; denominado por tópicos de astronomia, ou simplesmente astronomia.

A mais antiga das ciências, indispensável para a fundação da agricultura há 12 mil anos pela oferta do calendário - referência para a preparação, semeadura da terra e determinação das colheitas -, a astronomia sempre cumpriu uma função de sistematização da máquina do mundo. Assim, contribui para a ordenação simbólica das diferentes sociedades humanas. Os maias, certamente, não desenvolveram uma astronomia sofisticada por simples curiosidade. Assim, a cosmologia, ainda que possa passar despercebida por parte de milhões, de muitas maneiras está na base de uma ordenação com influência até mesmo na saúde mental da população mundial. [5, p. 23]

O tema foi escolhido, pois durante os dez anos passados da promulgação da LDB/96, e apesar das sugestões feitas pelos $\mathrm{PCN}, \mathrm{PCN}^{+}$pouco se percebeu, em sala de aula, assuntos relacionados aos tópicos de astronomia apesar de ser um tema que sempre chama atenção e por diversas vezes estar presente na mídia. Pesquisas mostram que tópicos de astronomia despertam interesse por partes de alunos como citados por Oliveira et al. [6] "os tópicos relativos a essas questões que comumente aguçam a curiosidade do jovem", Scalvi et al. [7] "astronomia é uma das áreas que mais atrai a atenção e desperta a curiosidade dos estudantes, desde os primeiros anos escolares até sua formação nos cursos de graduação, abrangendo todas as áreas, principalmente de física".

Para verificar como o tema astronomia estava sendo desenvolvido em sala de aula, optou-se por aplicar um questionário junto aos professores que ministram o conteúdo de física no ensino médio, na rede estadual de ensino dos municípios de Rio Grande da Serra, Ribeirão Pires e Mauá subordinada à Diretoria de Ensino de Mauá, no estado de São Paulo.

A presente pesquisa tem por finalidade averiguar se os tópicos de astronomia estão sendo abordados no ensino médio pelos professores de física da rede estadual de ensino e de que maneira vem sendo feita. Portanto, procurou-se investigar quem é o profissional que atua no ensino médio através de sua graduação e formação, pois se acredita que o aprendizado do professor tenha grande influência em seu fazer docente.

Muitas das necessidades e dificuldades de formação e de exercício da profissão apontadas, além de guardar uma relação direta com o desenvolvimento e a estruturação do professor-pessoa, como resultado de processos de maturação interna e de possibilidades de aprendizagem e de experiências do próprio sujeito, estão, ainda, intimamente relacionadas com a função social da própria formação, ou seja, com a transmissão de saberes, de saber-fazer e de saber-ser professor, principalmente no que se refere às questões do conhecimento científico, do uso das tecnologias e da inserção, no currículo, de problemáticas sociais. [8, p. 223]

Outra preocupação da pesquisa foi a de verificar quais recursos são utilizados no ensino de física dando um enfoque especial aos tópicos de astronomia. Houve, porém, a necessidade de se investigar quais os conteúdos gerais são aplicados em física no ensino médio e se algum conteúdo específico de astronomia é abordado. Procurou-se avaliar se são feitas conexões entre conteúdos de física e astronomia.

É sabido que a Lei de Diretrizes e Bases (LDB/96) assegura às escolas autonomia para criação e o desenvolvimento de uma organização vinculada às realidades e características do meio social e da comunidade na qual se inserem. O professor, portanto, tem um papel especial na organização pedagógica da escola: selecionar e planejar suas aulas, de acordo com a necessidade e realidade de seus alunos. $[9$, p. 22]

Para que a aprendizagem se torne verdadeiramente significativa o professor deve escolher e priorizar os 
conteúdos a serem trabalhados para o bom desenvolvimento do aluno, pois este deve levar em consideração seus conhecimentos prévios. Acredita-se, assim como mencionado nos $\mathrm{PCN}^{+}[4]$ que os jovens têm de ter uma compreensão de natureza cosmológica e que é na educação básica que esta ocorre, levando-os a um entendimento da origem e evolução do Universo em que vivem e que pretendem interagir e transformar.

\section{Metodologia}

Foi feito um questionário contendo quinze questões abertas, e aplicado junto aos professores que trabalham em escolas estaduais situadas nos municípios de Rio
Grande da Serra, Ribeirão Pires e Mauá, pertencentes à Diretoria de Ensino de Mauá, no estado de São Paulo durante o segundo semestre de 2006 e no decorrer do ano de 2007. A aplicação do questionário foi realizada com professores que lecionavam somente na modalidade de ensino dita regular (ver Tabela 1).

A presente pesquisa refere-se à aplicação ou não de tópicos de astronomia nas aulas de física e como ela acontece.

Por questões éticas, optou-se por omitir os nomes dos professores que responderam ao questionário. No decorrer da pesquisa, quando necessário eles foram identificados por Professor RGS (Rio Grande da Serra) 1, Professor RP (Ribeirão Pires) 2, Professor M (Mauá) 3 e assim sucessivamente.

Tabela 1 - Espaço amostral utilizado na pesquisa.

\begin{tabular}{|c|c|c|c|c|c|c|}
\hline Municípios & $\begin{array}{l}\text { Números de } \\
\text { escolas esta- } \\
\text { duais }\end{array}$ & $\begin{array}{l}\text { Escolas com } \\
\text { EM }\end{array}$ & $\begin{array}{l}\text { Escolas com } \\
\text { EM pesqui- } \\
\text { sadas }\end{array}$ & $\begin{array}{l}\text { Professores } \\
\text { de física por } \\
\text { município }\end{array}$ & $\begin{array}{l}\text { Professores } \\
\text { pesquisados }\end{array}$ & $\begin{array}{l}\text { Professores } \\
\text { pesquisados } \\
\text { em \% }\end{array}$ \\
\hline Rio Grande da Serra & 11 & 7 & 7 & 11 & 9 & 81,8 \\
\hline Ribeirão Pires & 30 & 17 & 17 & 30 & 16 & 53,3 \\
\hline Mauá & 61 & 29 & 18 & 30 & 22 & 73,3 \\
\hline
\end{tabular}

EM: ensino médio.

\section{Análise do questionário}

A seguir são apresentados resultados de algumas questões com as respectivas análises.

Para a análise da questão "Qual sua graduação?", foram considerados como espaço amostral os valores onze, vinte e dois e vinte e sete em função das respostas e não o número de professores que contribuíram com a pesquisa (nove, dezesseis e vinte e dois), pois existem professores com mais de uma graduação. Na opção outros estão incluídos os professores que não explicitaram o curso neste item. Para a elaboração da Fig. 1, foi levado em conta mais de uma graduação dos professores RGS 3, RGS 9, RP 2, RP 3, RP 6, RP 9, RP 11, RP 12, M 3, M 16, M 19, M 21 e M 22.

Em Rio Grande da Serra o professor RGS 3 tem graduação em matemática e pedagogia e o RGS 9 em física e química; enquanto que em Ribeirão Pires dos entrevistados seis possuem mais de uma graduação; sendo que três professores RP 2, RP 6, RP 9 possuem graduação em física e química, RP 11, RP $12 \mathrm{em}$ matemática e ciências físicas e biológicas e RP 3, em matemática e física. Em Mauá, dos entrevistados cinco possuem mais de uma graduação. Dois professores M 3, M 21 possuem graduação em física e matemática, o professor M 16 possui graduação em ciências físicas e pedagogia, M 19 em matemática e administração, e o professor M 22 possui graduação em matemática e engenharia elétrica.

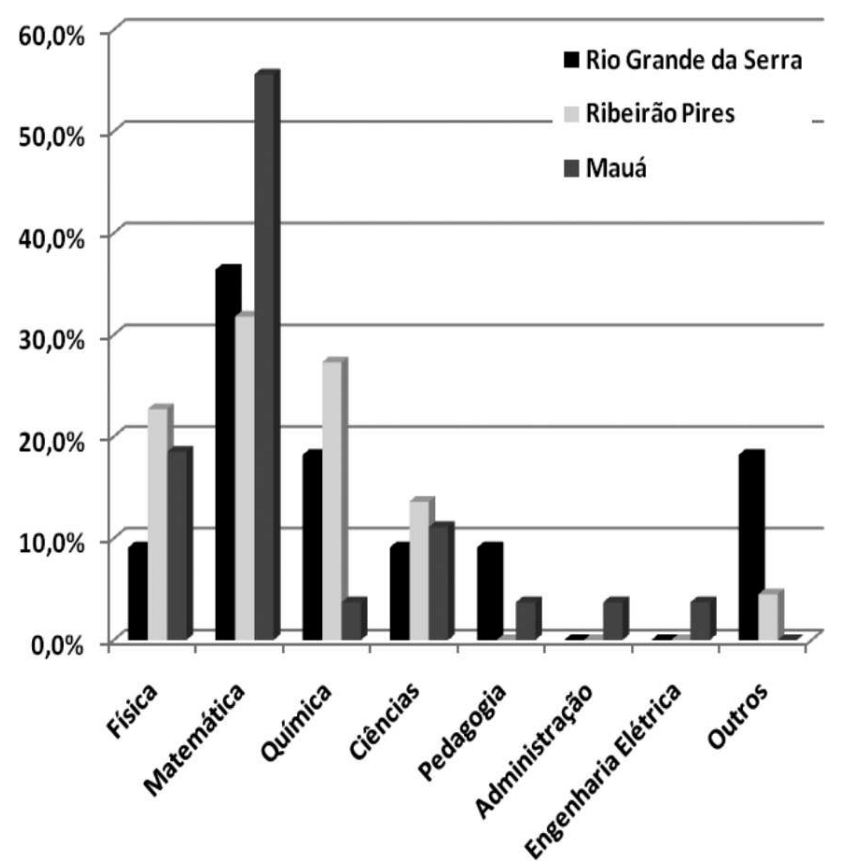

Figura 1 - Graduação dos docentes.

Graduação significa "curso de nível universitário, faculdade." [10, p. 1472]. Fica aqui entendido graduação como formação inicial.

Pela Fig. 1 observa-se que a maioria dos profissionais tem graduação em matemática, a saber: em Rio Grande da Serra 36,4\% dos pesquisados, Ribeirão 
Pires $31,8 \%$ e em Mauá 55,6\%. Nota-se também pela Fig. 1 que número de graduados em química lecionando o conteúdo de física na região é significativo, sendo que nos municípios de Rio Grande da Serra e Ribeirão Pires estes superam os graduados em física. Como estes municípios se situam no ABC paulista na região metropolitana de São Paulo onde se encontra também o pólo petroquímico, as faculdades da região apresentam um maior número de cursos em química. Os profissionais que não são absorvidos pela indústria ingressam ao magistério, justificando assim o número de graduados em química ministrando o componente curricular de física.

Para a pergunta "Você aborda tópicos de astronomia em algumas das séries do ensino médio?" foi considerado somente sim ou não, incluindo na resposta afirmativa referências como: raramente, algumas vezes.

Apesar de assuntos relacionados à astronomia sempre despertarem interesse nos alunos nota-se pela Fig. 2 que este conteúdo ainda é pouco utilizado pelos professores. Dos docentes pesquisados em Ribeirão Pires $(62,5 \%)$, Mauá $(63,6 \%)$ e Rio Grande da Serra $(44,4 \%)$ não faziam qualquer referência a esses tópicos em suas aulas.

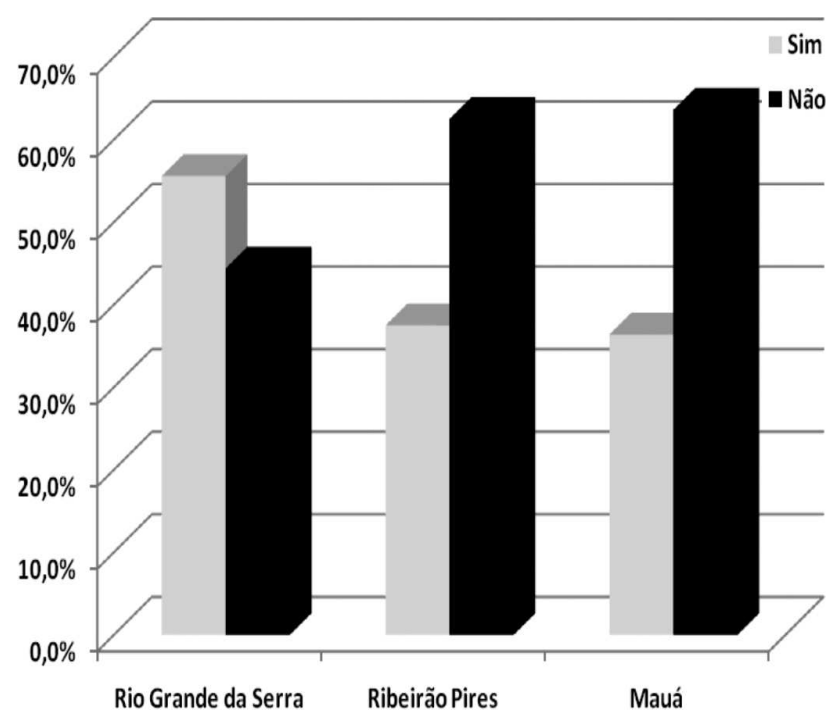

Figura 2 - Abordagem dos tópicos de Astronomia.

Em relação ao questionamento "Há quanto tempo você leciona física?", a Fig. 3 mostra que a maioria dos professores que estão em sala de aula lecionando a disciplina atua a menos de dez anos na rede estadual. Este fato é verificado nas três cidades.

Para se mapear os conteúdos de física ministrados em cada série foi feito o seguinte questionamento: "Quais os tópicos de física são abordados em cada uma das séries?" As Figs. 4, 5 e 6 apresentadas a seguir dão uma visão dos assuntos ensinados nas escolas estaduais nos municípios de Rio Grande da Serra, Ribeirão Pires e Mauá.

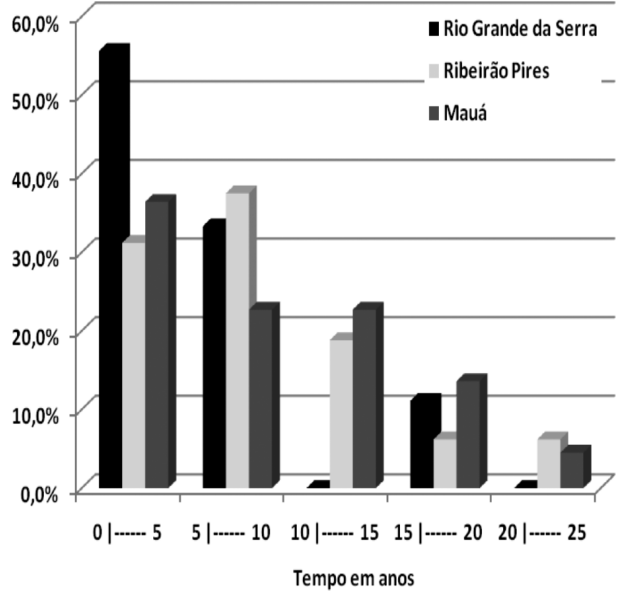

Figura 3 - Tempo que os docentes lecionam a disciplina de física.

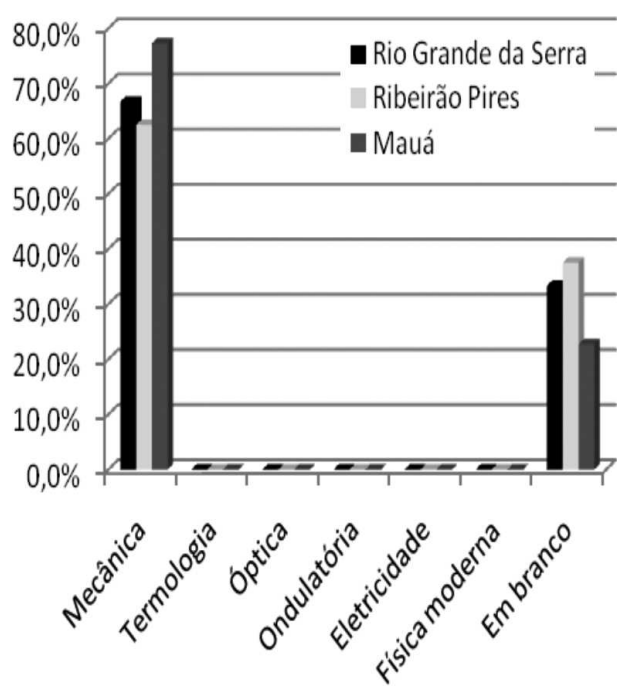

Figura 4 - Conteúdos de física aplicados pelos docentes no $1^{\circ}$ ano do ensino médio.

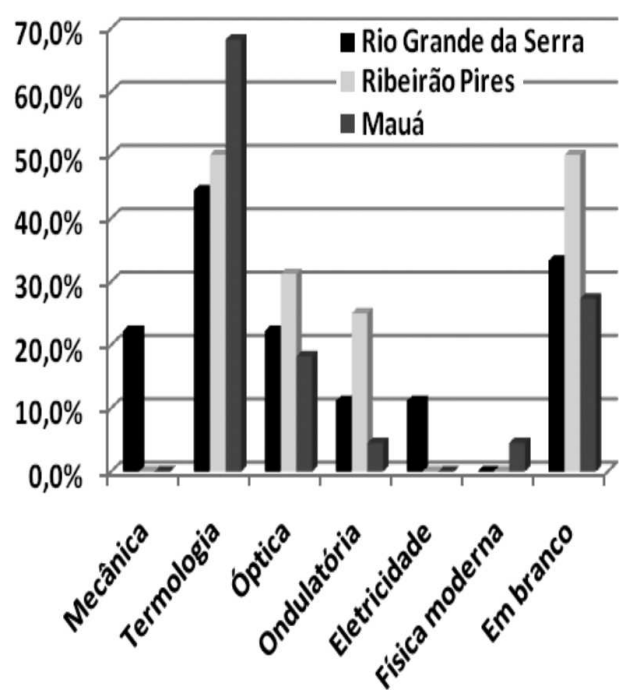

Figura 5 - Conteúdos de física aplicados pelos docentes no $2^{\circ}$ ano do ensino médio. 


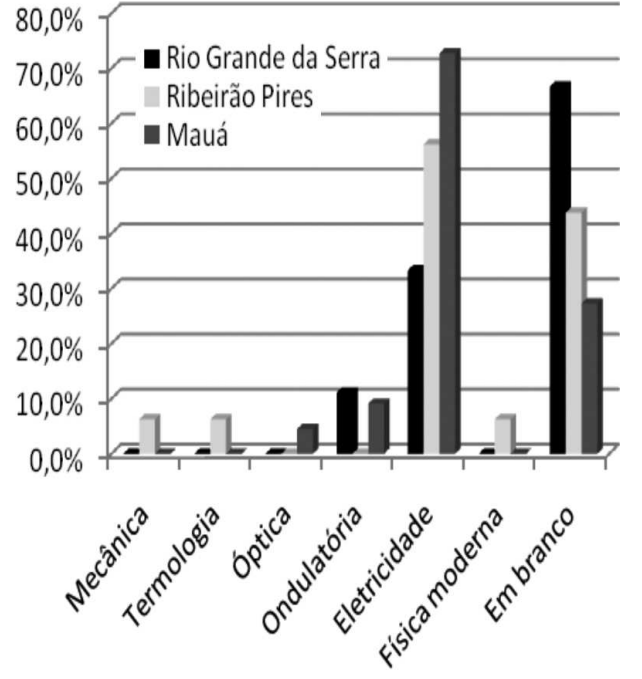

Figura 6 - Conteúdos de física aplicados pelos docentes no $3^{\circ}$ ano do ensino médio.

Para a construção das Figs. 4, 5 e 6 dividiu-se os conteúdos segundo Fuke et al. [11, 12, 13] em mecânica, termologia, óptica, ondulatória e eletricidade.

Foi considerado como mecânica os conteúdos listados pelos professores como: movimento uniforme, movimento variado, cinemática (incluindo vetorial), trabalho, potência, força, dinâmica, medidas de unidades, grandezas físicas, potência de dez, notação científica, sistema de unidades (sistema internacional), gráficos (confecção e interpretação) movimentos: variações e conservações, gravitação universal, velocidade, aceleração, vetores, leis de Newton e energia mecânica. Em Termologia considerou-se temperatura, transformação de escalas termométricas, propagação de calor, mudanças de estado físico, dilatação térmica, calorimetria. Em óptica foi considerado o termo luz, refração, reflexão da luz. Em Ondulatória foi considerado também o termo ondas, som já em Eletricidade incluiu-se termos como elétrica e eletromagnetismo, eletrostática, eletrodinâmica, campo elétrico, potencial elétrico, corrente elétrica, energia elétrica, resistores, associações de resistores, geradores e receptores elétricos, capacitores, eletrônica e os computadores, campo magnético e indução eletromagnética, bem como equipamentos elétricos.

Nota-se pela maneira que os conteúdos foram descritos, que a escolha de assuntos a serem ministrados em aula é principalmente baseada nos livros didáticos disponíveis no mercado e que raramente fazem referências a tópicos de astronomia.

Entretanto os professores RP 2, RP 4, M 11 e M 13 citaram conteúdos abordados em astronomia tais como: RP 2 não especificou as séries, mas abordou nascimento do Universo, formação das galáxias, estrelas, quasares, pulsares, super novas, nascimento e morte de estrelas, buracos negros, lei da gravitação universal, leis de Kepler, energia, ondas, velocidade de expansão, efeito Doppler e óptica; e RP 4 no primeiro ano se referiu a Terra e Universo. O professor M 11 citou criação do Universo e planetas e o professor M 13 referiu-se às fases da Lua, movimento de rotação e de translação da Terra.

No terceiro ano, o professor RP 4 se referiu à física moderna mencionando os conteúdos matéria e radiação; e o professor M 22 abordou os seguintes conteúdos de física moderna no segundo ano: passagem da física clássica para moderna (histórico), modelos atômicos, propriedades físicas da matéria, semicondutores e suas aplicações.

Verificou-se que somente uma pequena minoria menciona assuntos relacionados à astronomia e física moderna em suas aulas de acordo com as orientações sugeridas pelo $\mathrm{PCN}^{+}$

Para a questão "Qual a sua formação?", os resultados obtidos mostram que além da formação inicial (graduação), quais são os cursos que fazem parte do aprimoramento profissional. Para a construção da Fig. 7 foi contabilizado apenas um único curso de graduação, especialização, extensão entre os professores que possuíam dois ou mais cursos dentro da mesma modalidade.

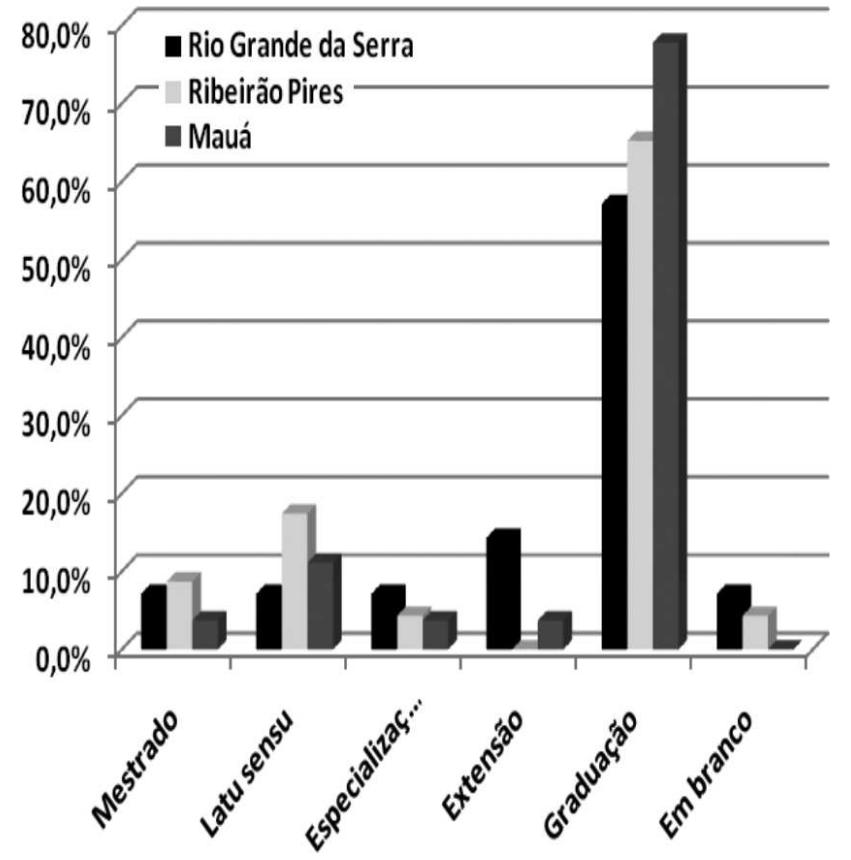

Figura 7 - Formação dos docentes.

Para ficar em conformidade com as respostas dadas pelos docentes, manteve-se a diferenciação feita pelos mesmos entre latu sensu e especialização.

Segundo Houaiss [10] formação significa "conjunto de conhecimentos e habilidades específicos de um determinado campo de atividade prática ou intelectual; conjunto dos cursos concluídos e graus obtidos por uma pessoa".

Os cursos citados pelos professores foram: especialização em matemática financeira (RGS 1), latu sensu em psicopedagogia (RGS 4), extensões em astronomia 
e astrofísica e ao de óptica e física moderna (RGS 5), mestrado em física nuclear (RGS 9), latu sensu em meio ambiente (RP 2), especialização em informática na educação e mestrado educação e currículo (RP 5), mestrado em física nuclear (RP 9), latu sensu em matemática aplicada e em educação matemática (RP 11), latu sensu em educação matemática (RP 12), latu sensu em educação matemática, extensão em mídias e tecnologias na educação e mestrado em ensino de matemática e ciências (M 2), latu sensu em gestão educacional (M 3), especialização em ensino de matemática (M 15) e latu sensu em magistério do ensino superior (M16).

A análise obtida para a pergunta "Qual a importância da astronomia na formação do aluno do ensino médio?" indica que a maior parte dos professores pesquisados admite que o ensino de astronomia é importante na formação do jovem que cursa o ensino médio.

A Fig. 8 mostra que a grande maioria dos docentes pesquisados nas três cidades concorda que o conhecimento em astronomia é necessário na formação do aluno. Em Rio Grande da Serra (seis), Ribeirão Pires (treze) e em Mauá (dezesseis) dos entrevistados afirmam ser importante que este conhecimento chegue ao aluno para que o mesmo possa entender e compreender a origem e o desenvolvimento do Universo e em particular o planeta Terra; pois o assunto desenvolve a imaginação, desperta curiosidade e interesse, além de ser um tema interessante e instigante. Os professores RGS 7, M 7, M 10 e M 19 afirmaram que nos dias atuais este assunto não tem a menor importância; sendo que M 10 e M 19 não deram qualquer justificativa. O professor RGS 7 mencionou que saber de fatos relacionados a astronomia como por exemplo o rebaixamento do planeta Plutão não faz sentido para o aluno; já o professor M 7 afirmou que assuntos relacionados aos conceitos astronômicos só tem importância para quem pretende fazer física. Deixaram a questão em branco os docentes RGS 2, RGS 6, RP 6, RP 13, RP 16, M 3, M 8 e M 18.

Ao ser perguntado em relação à utilização de novas tecnologias por meio da questão "Você usa programas computacionais voltados à astronomia?", observou-se que estas ainda não fazem parte do cotidiano dessas escolas estaduais. A Fig. 9 mostra que os professores pesquisados não utilizaram qualquer tipo de programa, a saber: em Rio Grande da Serra sete (77,8\%), Ribeirão Pires quinze $(93,8 \%)$ e Mauá vinte $(90,9 \%)$.

Os professores que responderam afirmativamente a questão utilizam os programas como Google Mars, Word Wind, Google Earth, Google Moon.

Segundo Pires e Veit [14] a inserção de Tecnologias de Informação e Comunicação (TICs) propicia um aumento na carga horária nas aulas de física (reclamação constantemente feita por professores), produz ganhos na aprendizagem dos alunos, além de permitir que notícias com informações de astronomia que raramente são discutidas em aula e muito menos contextualizadas em um assunto específico de física, apresentados pelos meios de comunicação possam ser compreendidos pelos estudantes.

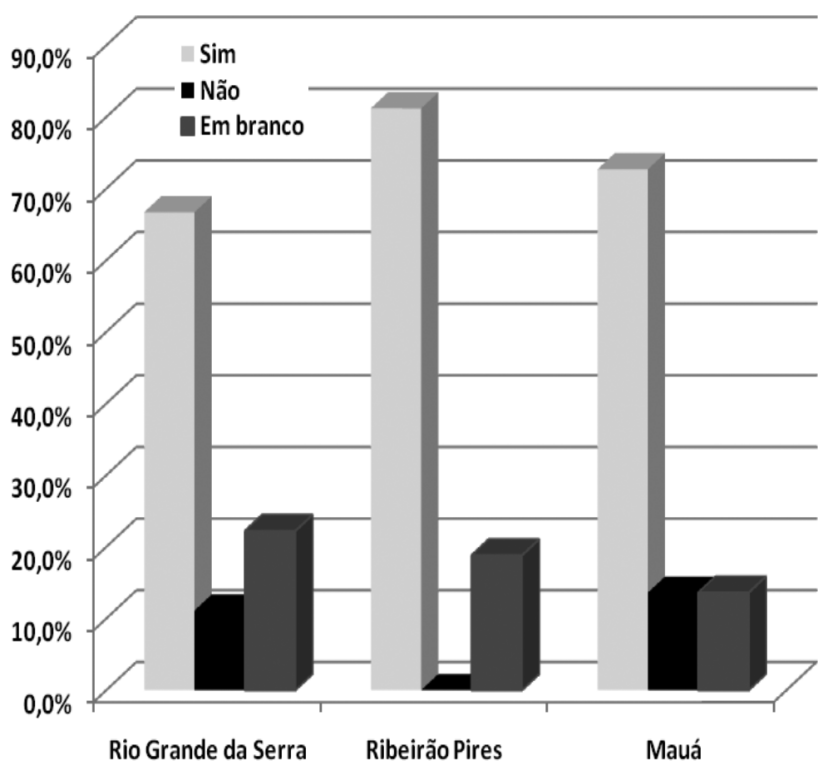

Figura 8 - Importância da Astronomia na formação do aluno.

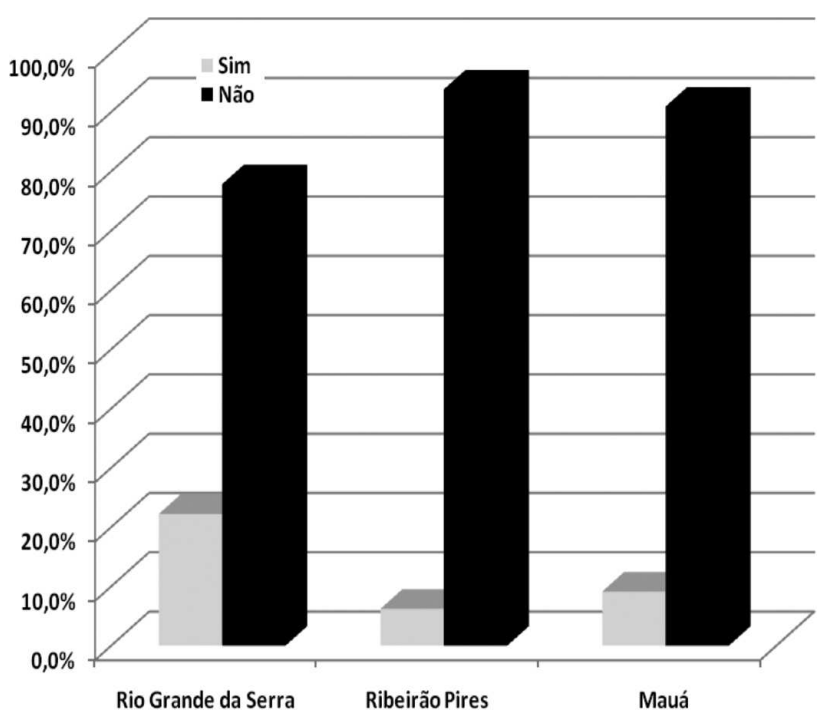

Figura 9 - Utilização de programas computacionais.

Em relação a questão "Você faz uma conexão na sua aula de física com os conceitos astronômicos? Qual?" os dados apresentados foram em Rio Grande da Serra: teoria do heliocentrismo, movimento dos planetas, gravidade, quando algum fato referente à astronomia é divulgado pela mídia, $1^{\mathrm{a}}$ e $3^{\mathrm{a}}$ leis de Newton, propagação do som através da análise de filmes de ficção científica, visão de espaço e proporção.

Em Ribeirão Pires: velocidade escalar, óptica, ondas, energia, trajetória, gravidade, visão de espaço, proporção, gravitação universal, movimentos dos planetas, centro de gravidade e leis de Newton. Sendo que os professores RP 13 e RP 15 não especificaram as conexões feitas e RP 14 deixou a questão em branco. 
No município de Mauá: aceleração da gravidade dos planetas e da Lua, situar o homem no espaço, criação do universo nascimento e morte das estrelas, campo magnético, lei da gravitação universal, leis de Kepler, fases da Lua, movimentos da Terra (translação e rotação), lançamento de foguete e satélite, microgravidade. Pela Fig. 10 o número de professores que fazem estas conexões ainda é muito pequeno.

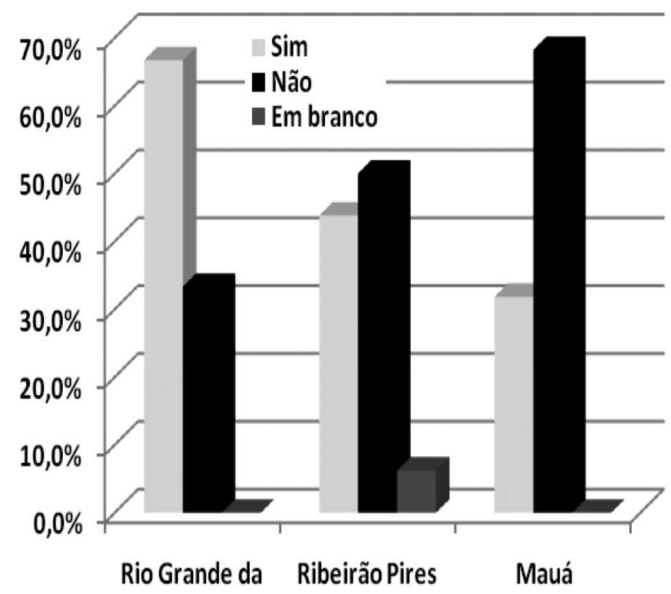

Figura 10 - Conexão nas aulas de física com os conceitos astronômicos nos municípios pesquisados.

$\mathrm{Na}$ questão, "Você utiliza laboratório nas suas aulas?" o resultado apresentado na Fig. 11 mostra que a grande maioria dos professores continua ignorando este recurso na aprendizagem dos alunos. Alguns dos pesquisados mencionaram que a escola não possui laboratório. Apesar disso o número de professores que utiliza do recurso levando experimentos para sala de aula ainda é muito baixo.

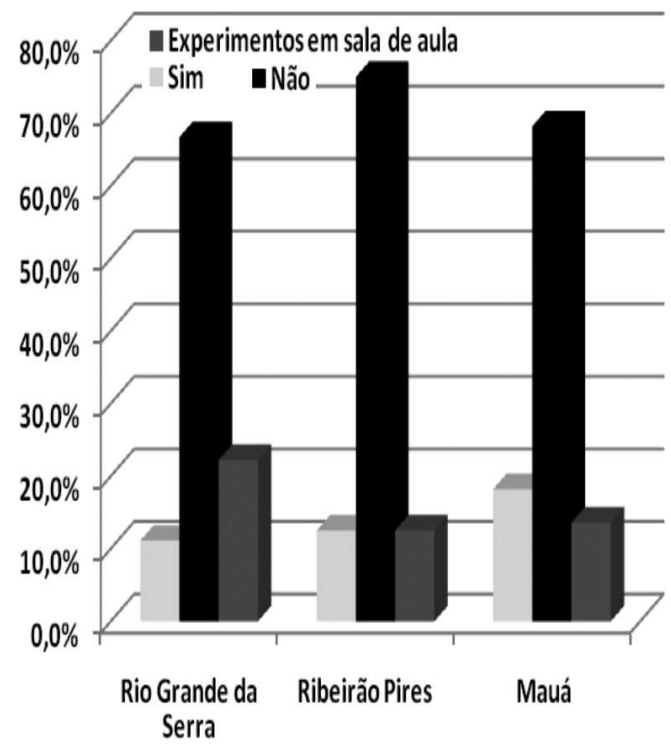

Figura 11 - Utilização de laboratórios.

A atividade experimental é um recurso que sempre chama a atenção dos alunos, sendo que segundo Araujo e Abib [15] os experimentos podem ser classificados quanto ao grau de direcionamento em: demonstração (possibilita ilustrar alguns aspectos dos fenômenos abordados), verificação (busca a verificação de alguma lei física ou de seus limites de validade) e investigação (onde ocorre a participação ativa do educando desde a construção do equipamento até a realização dos experimentos).

Pelas respostas obtidas dos professores verifica-se que os professores quando fazem uso de experimentos utilizam de atividades experimentais de demonstração e verificação.

Trabalhos voltados ao conteúdo de astronomia como o de Caniato [16], Afonso [17], Canalle e Souza [18] apresentam atividades experimentais (demonstração, verificação e investigação) que podem ser desenvolvidas com materiais simples sem necessariamente precisar de um laboratório (queixa constante dos professores de escolas públicas) solucionando assim o problema da não realização de aulas práticas, e melhorando, portanto o entendimento dos estudantes em relação aos fenômenos estudados.

Ao ser questionado "Que tópicos de astronomia você aplica? Em que série?" A Fig. 12 revela que dos professores pesquisados, a maioria não aplica tópicos de astronomia apesar de concordar com sua importância para a formação do aluno (Fig. 8).

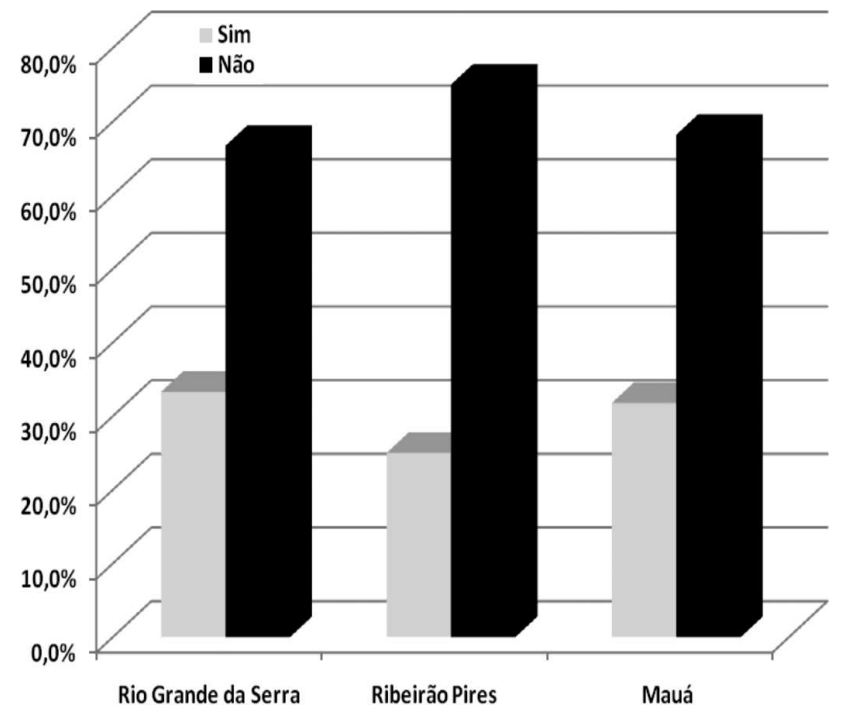

Figura 12 - Aplicação de tópicos de astronomia no ensino médio.

Em Rio Grande da Serra quando questionados a respeito de quais tópicos de astronomia são aplicados e em que série, os três professores que responderam afirmativamente citam a lei da gravitação universal, definição de planetas e demais corpos celestes na $1^{\mathrm{a}}$ série (RGS 5). O RGS 6 cita inércia, ação e reação também na $1^{\mathrm{a}}$ série; e o RGS 9 cita a teoria do big bang na $2^{\text {a }}$ série. Em Ribeirão Pires quatro professores responderam afirmativamente sendo que o RP 2 cita do big bang até a formação do planeta Terra na $3^{\mathrm{a}}$ série; RP 4 movimento dos planetas, sistema geocêntrico e gravitação univer- 
sal na $1^{\mathrm{a}}$ série; RP 8 gravitação universal também na $1^{\mathrm{a}}$ série e o RP 9 teoria do big bang na $2^{\mathrm{a}}$ série. Em Mauá, sete professores responderam afirmativamente sendo que o M 1 cita aceleração da gravidade $1^{\mathrm{a}}$ série; M 9 lei da gravitação universal, campo gravitacional, aceleração da gravidade, queda livre, massa e peso de um corpo na $1^{\mathrm{a}}$ e $2^{\mathrm{a}}$ séries; M 11 cita o filme Apollo 12, gravidade e velocidade dos planetas do Sistema Solar na $1^{\mathrm{a}}$ e $3^{\mathrm{a}}$ séries; M 12 lei da gravitação universal, leis de Kepler e aceleração da gravidade na $1^{\mathrm{a}}$ série; M 13 fases da Lua e os movimentos de rotação e translação da Terra; M 14 microgravidade e composição dos planetas e o M 16 cita as leis de Kepler. Os professores RGS 4, RP 1, RP 13, RP 14, RP 15 e RP 16 deixaram a questão em branco e foram incluídos na categoria não.

Ao ser analisada a questão "Você já levou alguma vez os seus alunos para o planetário e ou museu de ciências? Quantas vezes?" verificou-se que os professores que responderam afirmativamente a questão, foram à Estação Ciência e ao Show da Física, na Universidade de São Paulo (USP) e ao Eureca (Guarujá).

Ainda não é prática dos professores ocuparem espaços não formais para promover a aprendizagem, conforme Fig. 13. Uma das alegações feitas por eles para a não utilização desse espaço é o custo que precisa ser repassado para o aluno.

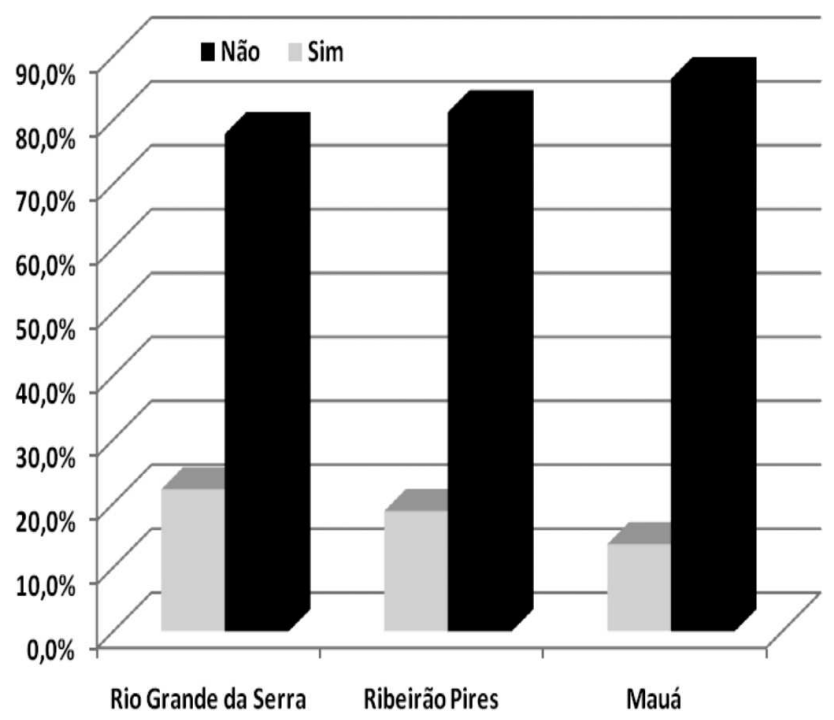

Figura 13 - Idas a museus e ou planetários.

Em relação à questão "Quais são os livros e ou revistas em astronomia que você indica para os seus alunos?" as indicações feitas pelos professores foram livros paradidáticos, biblioteca da escola, revistas $\mathrm{Su}-$ perinteressante, Veja, Halley, Scientific American no Brasil, Astronomy, Ciência Hoje, Galileu, National Geografic, internet e os livros Cosmos e Eram os Deuses Astronautas? (ver Fig. 14).

Em Rio Grande da Serra dois professores deixaram a questão em branco, quatro em Ribeirão Pires e três em Mauá. Os professores que deixaram as questões em branco foram incluídos na categoria não.

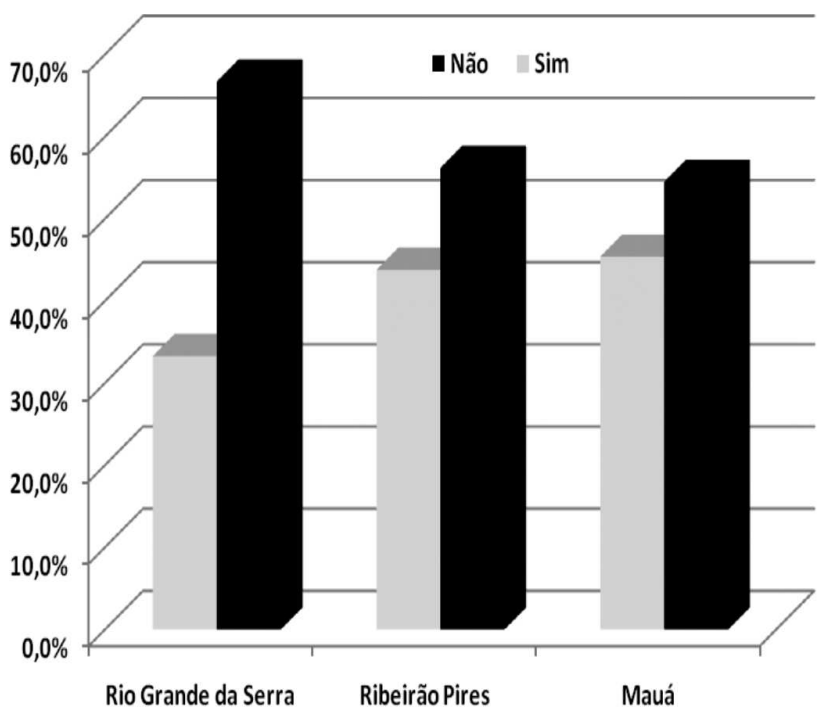

Figura 14 - Indicação de livros e ou revistas.

\section{Conclusões}

Desde a promulgação da LDB/96 e a implantação dos PCN e $\mathrm{PCN}^{+}$pouca mudança se observou nas escolas estaduais de Rio Grande da Serra, Ribeirão Pires e Mauá em relação à maneira de abordar o conteúdo de física e em particular de introduzir tópicos de astronomia ao currículo, apesar de já ter decorrido uma década. Segundo Rios [19] "sem o consentimento dos professores, mudanças não se realizam".

Apesar da sugestão feita pelos $\mathrm{PCN}^{+}$por temas estruturadores onde se percebe um enfoque CTS, notouse que grande parte das escolas e seus educadores ainda persistem em simplesmente transmitir conteúdos, sem relacioná-los com o mundo vivencial dos alunos.

Algumas vezes considera-se a escola simplesmente como instrumento para transferir uma certa quantidade de conhecimentos à nova geração. Mas isso não é correto. O conhecimento é morto; a escola, porém, serve aos vivos. Deveria desenvolver nos indivíduos jovens as qualidades e capacidades que são valor para o benefício da comunidade. (Albert Einstein na Ref. [20, p. 90])

Quando questionados sobre a aplicação dos tópicos de astronomia verificou-se que a grande maioria não aplica. Isto leva a crer que possivelmente a não aplicação dos tópicos de astronomia tem alguma relação com a graduação e formação dos professores.

Professores de ciências pouco sabem sobre os conceitos científicos envolvidos nos estudos sobre as estrelas, galáxias, o Universo, ou até mesmo sobre o Sistema Solar, pois, 
em sua formação, conhecimentos dessa natureza não fizeram parte do currículo escolar. [21, p. 48]

O mesmo é observado em relação aos professores do ensino médio. É sabido que nem mesmo o curso de física tem uma disciplina com o conteúdo voltado somente para a astronomia, tão pouco as demais graduações.

Para solucionar estes problemas faz-se necessário dotar de significado o conteúdo a ser ministrado, pois somente tornando-o verdadeiramente significativo para o professor, ele passa a fazer parte do fazer docente do mesmo, ou seja, só é possível ensinar aquilo que se sabe. Portanto deve-se:

Dotá-los de um saber fazer prático nos níveis e nas áreas do currículo que vão desenvolver, na organização das escolas, etc., oferecendo alternativas diversas. Um saber fazer que deve concretizar-se em modelos ou esquemas, não completamente fechados, de tarefas didáticas apropriadas para os alunos, de acordo com a especialidade que exerce. Não se trata de provê-los de modelos de conduta metodológica para reproduzir, mas de esquemas práticos moldáveis e adaptáveis segundo as circunstâncias, sem esquecer os fundamentos que lhes servem de apoio. [22, p. 271]

O incentivo na formação continuada pode contribuir para reduzir um problema da região, que é a falta de profissional graduado em física, além de proporcionar aos educandos um ensino de qualidade.

Criação de um núcleo de apoio aos professores Ribeiro [23], curso de astronomia básica de curta duração Pinto et al. [24] podem ser algumas das soluções para minimizar o atual quadro no ensino de astronomia na região.

Apesar da globalização, da facilidade de obter informações verificou-se que a maioria dos professores pouco ou quase nada utilizam de recursos como laboratório, internet, visitas, indicação de leituras como facilitador na aprendizagem do conteúdo (Figs. 12, 13 e 14), reiterando o ensino como sendo um processo de transmissão de informações compartimentadas e memorização.

A grande maioria dos professores concorda que tópicos de astronomia têm uma grande influência na formação do aluno do ensino médio, pois com este conhecimento o aluno passa a entender e compreender a origem e o desenvolvimento do Universo e em particular o planeta Terra; levando-o a perceber segundo Capozzolli [5] que "o encaminhamento de desafios como o aquecimento global pressupõe uma conscientização planetária de conceitos científicos, como forma de pressionar governos e empresas a adotar novos comportamentos". Mas fica aqui registrado que os professores de Rio Grande da Serra, Ribeirão Pires e Mauá muito ainda tem que caminhar para que tópicos de astronomia efetivamente façam parte de seus planejamentos.

\section{Referências}

[1] BRASIL, Lei n. 9.394, de 20 de dezembro de 1996. Estabelece as Diretrizes e Bases da Educação Nacional (Diário Oficial da União, Brasília, 1996).

[2] BRASIL, Parâmetros Curriculares Nacionais: Ensino Médio (Ministério da Educação, Brasília, 1999).

[3] C.G. Pimenta, in Saberes Pedagógicos e Atividade Docente (Cortez, São Paulo, 2002), $3^{\text {a }}$ ed., p. 15-34.

[4] BRASIL, PCN+ Ensino Médio: Orientações Educacionais Complementares aos Parâmetros Curriculares Nacionais - Ciências da Natureza, Matemática e suas Tecnologias (MEC/SEMTEC, Brasília, 2002).

[5] U. Capozzoli, Scientific American Brasil 61, 22 (2007).

[6] E.F. Oliveira, M.R. Voelzke e L.H. Amaral, Revista Latino-Americana de Educação em Astronomia 4, 79 (2007).

[7] R.M.F. Scalvi, T.O. Bernardes, R.R. Barbosa, G. Iachel, A.B. Neto e M.A.L. Pinheiro, Revista Brasileira de Ensino de Física 28, 391 (2006).

[8] M.D. Maciel, in Anais do III Seminário Ibérico CTS no Ensino de Ciências: Perspectivas Ciência-Tecnologia - Sociedade na Inovação da Educação em Ciência (Universidade de Aviero, Aviero, 2004), p. 221-224.

[9] E.M. Maia e Z. de F. Murrie (orgs), PEC (Projeto Escola e Cidadania). Manual do Professor. Física (Editora do Brasil, São Paulo, 2000), p. 22.

[10] A. Houaiss e M. de S. Villar, Dicionário Houaiss da Língua Portuguesa (Objetiva, Rio de Janeiro, 2001), $1^{\mathrm{a}}$ ed.

[11] L.F. Fuke, C.T. Shigekiyo e K. Yamamoto, Os Alicerces da Física (Saraiva, São Paulo, 1993a), $6{ }^{\text {a }}$ ed., v. 1, $384 \mathrm{p}$.

[12] L.F. Fuke, C.T. Shigekiyo e K. Yamamoto, Os Alicerces da Física (Saraiva, São Paulo, 1993b), $6{ }^{\text {a }}$ ed., v. 2, $432 \mathrm{p}$.

[13] L.F. Fuke, C.T. Shigekiyo e K. Yamamoto, Os Alicerces da Física (Saraiva, São Paulo, 1993c), 6 a ed., v. 3, $384 \mathrm{p}$.

[14] M.A. Pires e E.A. Veit, Revista Brasileira de Ensino de Física 28, 241 (2006).

[15] M.S.T. de Araújo e M.L.V. dos S. Abib, Revista Brasileira de Ensino de Física 25, 176 (2003).

[16] R. Caniato, O Céu (Fundação Tropical de Pesquisas e Tecnologia, Campinas, 1978), $3^{\text {a }}$ ed., v. 1.

[17] G.B. Afonso, Revista Brasileira de Ensino de Física 18, 149 (1996).

[18] J.B.G. Canalle e A.C.F. Souza, Caderno Brasileiro de Ensino de Física 22, 121 (2005).

[19] T.R. Rios, Compreender e Ensinar: Por uma Docência da Melhor Qualidade (Cortez, São Paulo, 2003), $4^{\mathrm{a}}$ ed., p. 11-13.

[20] I. Monteiro, in Einstein Reflexões Filosóficas (Alvorada, São Paulo, 1985), p. 89-97. 
[21] C. Leite e Y. Hosoume, Revista Latino-Americana de Educação em Astronomia 4, 47 (2007).

[22] J.G. Sacristán, O Currículo: Uma Reflexão Sobre a Prática (Artmed, Porto Alegre, 2000), $3^{\mathrm{a}}$ ed., 352 p.

[23] O.B. da S. Ribeiro, Formação de um Núcleo de Apoio
Regional a Professores de Física em Serviço no Ensino Médio Baseado na Universidade de Itaúna. Dissertação de Mestrado, UFMG, 2006.

[24] S.P. Pinto, O.M. da Fonseca e D.M. Vianna, Caderno Brasileiro de Ensino de Física 24, 71 (2007). 